University of Wollongong

Research Online

Faculty of Engineering - Papers (Archive)

Faculty of Engineering and Information

Sciences

$1-1-2011$

\title{
Strategies to enhance the removal of the persistent pharmaceutically active compound carbamazepine by membrane bioreactors
}

\author{
Xueqing Li \\ University of Wollongong,xql895@uow.edu.au \\ Faisal I. Hai \\ University of Wollongong, faisal@uow.edu.au \\ Nichanan Tadkaew \\ University of Wollongong, nt84@uow.edu.au \\ Sara Gilbertson \\ University of Wollongong \\ Long Nghiem \\ University of Wollongong, longn@uow.edu.au
}

Follow this and additional works at: https://ro.uow.edu.au/engpapers

Part of the Engineering Commons

https://ro.uow.edu.au/engpapers/3387

\section{Recommended Citation}

Li, Xueqing; Hai, Faisal I.; Tadkaew, Nichanan; Gilbertson, Sara; and Nghiem, Long: Strategies to enhance the removal of the persistent pharmaceutically active compound carbamazepine by membrane bioreactors 2011, 402-407.

https://ro.uow.edu.au/engpapers/3387

Research Online is the open access institutional repository for the University of Wollongong. For further information contact the UOW Library: research-pubs@uow.edu.au 


\title{
Strategies to enhance the removal of the persistent pharmaceutically active compound carbamazepine by membrane bioreactors
}

\author{
Xueqing Li, Faisal Ibney Hai , Nichanan Tadkaew, Sara Gilbertson and Long Duc Nghiem \\ School of Civil, Mining and Environmental Engineering, University of Wollongong, NSW 2522, \\ Australia \\ *Corresponding author: Faisal Hai. Tel: (+61 2) 4221 3054. Email: faisal@uow.edu.au.
}

\begin{abstract}
Carbamazepine, which is an anti-epileptic drug, is ubiquitously present in municipal wastewater. Owing to its recalcitrant chemical structure, carbamazepine is not significantly removed during conventional biological treatment or even by membrane bioreactor (MBR). With the ultimate aim of providing insights into the strategies to enhance carbamazepine removal, the effect of key operational parameters, namely, loading rate (2-750 $\mu \mathrm{g} / \mathrm{L} . \mathrm{d})$, $\mathrm{pH}(5-9)$, mixed liquor suspended solids (MLSS) concentration (1-15 g/L) and dissolved oxygen (DO) $(<0.5-5 \mathrm{mg} / \mathrm{L})$ on the removal of carabamazepine by MBR was systematically studied. Results obtained in this study revealed negligible influence of $\mathrm{pH}$ and of MLSS concentration (beyond $5 \mathrm{~g} / \mathrm{L}$ ) on the removal of carbamazepine. The removal rate, however, was significantly enhanced under a DO concentration of less than $0.5 \mathrm{mg} / \mathrm{L}$, suggesting that an alternating anoxic-oxic environment in MBR would achieve high removal. Significantly enhanced (287 mg/gm vs. $0.02 \mathrm{mg} / \mathrm{gm}$ ) adsorption of carbamazepine on powdered activated carbon (PAC) as compared to MBR sludge indicated that simultaneous PAC adsorption in MBR may achieve enhanced removal.
\end{abstract}

Keywords: carbamazepine; enhanced removal; membrane bioreactor; pharmaceutically active compound; dissolved oxygen; wastewater.

\section{Introduction}

There is an increasing concern about the presence of pharmaceutical compounds in the environment due to the potential risk to the aquatic environment. A large volume of pharmaceuticals are used per year with different purposes such as prevention, diagnosis and treatment of diseases in humans and animals. Due to the incomplete human metabolism and discharge into the waste stream, pharmaceuticals are found in environment. In the last decade, researchers have detected numerous pharmaceuticals in the aquatic environment [1].

Effluents from wastewater treatment plants (WWTPs) can be considered to be one of the most important sources of pharmaceuticals in the environment [2]. Conventional WWTPs are not specifically designed to remove pharmaceuticals and other micropollutants. As a result of ineffective removal, they pass through WWTPs and are widely detected in downstream water bodies, with concentrations cascading from WWTP effluents, to surface waters, to groundwater.

Carbamazepine, which is an anti-epileptic drug, is composed of two benzene rings fused to an azepine group, which in turn is connected to an amide group. It is ubiquitously present in municipal wastewater and due to its chemical stability it is not significantly removed during conventional biological treatment. Accordingly, this compound has been frequently detected in the effluents of wastewater treatment plants at concentration of up to tens of $\mu \mathrm{g} / \mathrm{L}[3]$. In a survey conducted by Ternes [1], carbamazepine was detected in all 30 WWTP effluents with a 90- percentile of 3700 $\mathrm{ng} / \mathrm{L}$ and in 24 of 26 samples from 20 rivers with a 90-percentile of $820 \mathrm{ng} / \mathrm{L}$. The maximum concentration of carbamazepine in WWTP effluents was $6300 \mathrm{ng} / \mathrm{L}$, which was also the maximum detected concentration of all 32 drugs in the survey. In surface waters, carbamazepine usually

Li, X., Hai, F. Ibney., Tadkaew, N., Gilbertson, S. \& Nghiem, L. Duc. (2011). Strategies to enhance the removal of the persistent pharmaceutically active compound carbamazepine by membrane bioreactors. Desalination and Water Treatment, 34 (1-3), $402-407$. 
occurs at relatively low concentrations (tens of ng/L). The highest detected concentration (1075 $\mathrm{ng} / \mathrm{L}$ ) of carbamazepine in surface water was found in Berlin [4]. It has been also detected in sea water, although at a very low concentration (2 ng/L) [5]. Pharmaceutical residues can be introduced into groundwater through surface water filtration, leakage, and groundwater recharge. Carbamazepine has been detected in the groundwater at concentrations from few tens [6] up to 610 ng/L [7].

Due to its persistence in WWTPs, carbamazepine has been proposed as an anthropogenic marker to assess effluent quality. Even the combination of conventional activated sludge treatment, sand filtration, and ozonation could not achieve more than 60\% removal of carbamazepine [8]. In addition to chemical stability, their poor removal has been partly attributed to their hydrophilic nature $(\log \mathrm{D}<3)$. Membrane Bioreactor $(\mathrm{MBR})$ is a proven technology to achieve better levels of typical water quality parameters like total organic carbon (TOC) and total nitrogen (TN). However, to date both laboratory scale and pilot scale MBR plant studies have reported negligible to moderate removal (usually less than 10\%) of carbamazepine. Even the application of a sludge retention time (SRT) of as long as 500 days did not improve carbamazepine removal in a study conducted by Clara et al [9]. Studies have heavily reported the limited extent of carbamazepine removal, but to date fewer studies have attempted to investigate the governing reasons. Consequently no definitive strategy to solve this problem has been reported to date.

In this study, we investigated the effect of different operational parameters namely carbamazepine loading, $\mathrm{pH}$, dissolved oxygen (DO) and mixed liquor suspended solid (MLSS) concentration on the removal of carbamazepine in laboratory scale MBRs. Based on the results from our study coupled with a comprehensive literature review we provide insights into the strategies to enhance the removal of carbamazepine in MBR. According to our knowledge, this is the first study which comprises investigation into a set of important factors, rather than a single factor.

\section{Materials and methods}

\subsection{Synthetic wastewater}

A synthetic wastewater simulating municipal sewage was used to ensure a stable feeding rate throughout the experiment. Concentrated stock solution was prepared and stored in a refrigerator at $4{ }^{\circ} \mathrm{C}$. It was then diluted with MilliQ water on a daily basis to make up a feed solution containing glucose $(400 \mathrm{mg} / \mathrm{L})$, peptone $(75 \mathrm{mg} / \mathrm{L}), \mathrm{KH}_{2} \mathrm{PO}_{4}(17.5 \mathrm{mg} / \mathrm{L}), \mathrm{MgSO}_{4}(17.5 \mathrm{mg} / \mathrm{L}), \mathrm{FeSO}_{4}(10$ $\mathrm{mg} / \mathrm{L})$, and sodium acetate $(225 \mathrm{mg} / \mathrm{L})$. This composition was based on a previous study [10]. A concentrated stock solution of carbamazepine was prepared in pure methanol. The trace organic stock solution was kept in a freezer and was used within less than a month. A specific amount of stock solution was mixed with the synthetic wastewater to achieve the required influent carbamazepine concentration. All chemicals used were of analytical grade.

\subsection{Laboratory scale MBR system}

A laboratory-scale MBR system was used in this study. Detailed description of this MBR system is available elsewhere[11]. The system consisted of a glass reactor, a continuous mixer, two air pumps, a pressure sensor, and influent and effluent pumps. Two ZeeWeed-1 (ZW-1) submerged hollow fibre ultrafiltration membrane modules supplied by Zenon Environmental (Ontario, Canada) were used in this set-up. The membrane has a nominal pore size of $0.04 \mu \mathrm{m}$. Each module has an effective membrane surface area of $0.047 \mathrm{~m}^{2}$. The hydraulic retention time was set at 24 hours, corresponding to a permeate flux of $4.3 \mathrm{~L} / \mathrm{m}^{2} \mathrm{~h}$. The MBR $\mathrm{pH}$, temperature and dissolved oxygen (DO) content were kept constant at $7,20.0 \pm 0.1^{\circ} \mathrm{C}$ and $2 \pm 1 \mathrm{mg} / \mathrm{L}$, respectively. The MBR was seeded with activated sludge from the Wollongong sewage treatment plant, NSW, Australia. After

Li, X., Hai, F. Ibney., Tadkaew, N., Gilbertson, S. \& Nghiem, L. Duc. (2011). Strategies to enhance the removal of the persistent pharmaceutically active compound carbamazepine by membrane bioreactors. Desalination and Water Treatment, 34 (1-3), $402-407$. 
the initial start-up process, which lasted about 2 months, a small amount of sludge was regularly extracted from the reactor to keep the sludge age at approximately 70 days. Performance of the MBR system with regard to basic water quality parameters was then monitored for an extended period of more than four weeks, after which the investigation on the effect of carbamazepine loading (2-6 $\mu \mathrm{g} / \mathrm{L.d})$ and $\mathrm{pH}(5-9)$ of the reactor, respectively on removal were conducted. The MLSS concentration in the reactor during this part of the investigation was around $15 \mathrm{~g} / \mathrm{L}$. A similar MBR system was then inoculated by the sludge taken from the first MBR. The second MBR was subject to high carbamazepine loading (750 $\mu \mathrm{g} / \mathrm{L} . \mathrm{d})$ and was operated under a DO of less than 0.5 $\mathrm{mg} / \mathrm{L}$ from the beginning. The effect of MLSS of this MBR on removal was studied as the MLSS increased from the initial level of only $1 \mathrm{~g} / \mathrm{L}$ to $11 \mathrm{~g} / \mathrm{L}$. The MLSS concentration remained fairly stable beyond this period. The effect of DO concentration on removal was subsequently studied by operating the MBR under a DO of $0.5 \mathrm{mg} / \mathrm{L}$ for further 30 days and then under higher DO levels (2$5 \mathrm{mg} / \mathrm{L})$.

\subsection{Analytical techniques}

The analysis of the model trace organic was based on a previously reported method [11-12]. The target compound was extracted using $5 \mathrm{~mL}, 500 \mathrm{mg}$ hydrophilic/lipophilic balance (HLB) cartridges (Waters, Millford, MA, USA). After elution the analyte was separated using an Agilent (Palo Alto, CA, USA) 1200 series high performance liquid chromatography (HPLC) system equipped with a 150 x $4.6 \mathrm{~mm}, 5 \mu \mathrm{m}$ particle size, Luna C18 (2) column (Phenomenex, Torrence CA, USA). Mass spectrometry was performed using an API 4000 triple quadrupole mass spectrometer (Applied Biosystems, Foster City, CA, USA) equipped with a turbo-V ion source employed in both positive and negative electro-spray modes. When high concentration of carbamazepine $(750 \mu \mathrm{g} / \mathrm{L})$ was used in the feed solution, a Shimadzu HPLC system equipped with an UV-Vis detector was used for the analysis.

Conductivity and $\mathrm{pH}$ were measured using an Orion 4-Star Plus $\mathrm{pH} /$ conductivity meter. Total organic carbon (TOC) and total nitrogen (TN) were analysed using a Shimadzu TOC/TN-V $\mathrm{V}_{\mathrm{CSH}}$ analyser (Tokyo, Japan). TOC analysis was conducted in non-purgeable organic carbon (NPOC) mode. Samples were kept at $4^{\circ} \mathrm{C}$ until analysed and calibrations were performed in the range between 0 and $1000 \mathrm{mg} / \mathrm{L}$ and 0 to $100 \mathrm{mg} / \mathrm{L}$ for TOC and TN, respectively. MLSS and MVLSS contents in the MBR were measured in accordance to the Standard Methods for the Examination of Water and Wastewater [13].

\section{Results and discussion}

\subsection{Effect of loading rate}

The basic water quality parameters such as TOC and TN were continuously monitored to confirm biological stability. Apart from the trial on the effect of $\mathrm{pH}$ (section 3.2) the TOC and TN removal rates were stable throughout the operation period (data not shown). Carbamazepine removal rate in our study ranged from 3-22\% depending on the loading rate (Table 1 ). The low \% removal in general is in line with the literature reports and demonstrates once again the hardly biodegradable nature of carbamazepine. Löffler et al. [14] found that carbamazepine was highly recalcitrant to elimination in a water/sediment system at laboratory scale. The time required for a $50 \%$ reduction of its initial concentrations $(100 \mu \mathrm{g} / \mathrm{L})$ was 328 days, as calculated by first-order elimination kinetics. Stamatelatou et al. [15] conducted a biodegradability test of carbamazepine in sodium acetate cultured activated sludge in both sea and fresh water. They observed no biodegradation of carbamazepine at an initial concentration of $0.5 \mathrm{mg} / \mathrm{L}$ in either sea or freshwater. Carbamazepine was classified in biodegradability group of below $0.1 \mathrm{~L} / \mathrm{kg}_{\mathrm{ss}} / \mathrm{d}$ when considering a first order degradation constant $\left(\mathrm{k}_{\mathrm{biol}}\right)$ in WWTPs [16]. Apart from the batch studies, to date both laboratory

Li, X., Hai, F. Ibney., Tadkaew, N., Gilbertson, S. \& Nghiem, L. Duc. (2011). Strategies to enhance the removal of the persistent pharmaceutically active compound carbamazepine by membrane bioreactors. Desalination and Water Treatment, 34 (1-3), $402-407$. 
and pilot scale MBR plant studies have reported negligible [17-19] to moderate [20-23] removal, usually less than $10 \%$. The low removal rate observed in our study is, hence, in close agreement with the prior reports.

In our study, although the \% removal rate was larger in case of the lower loading rate (2-6 $\mu \mathrm{g} / \mathrm{L} . \mathrm{d})$ operation as compared to the higher loading rate $(750 \mu \mathrm{g} / \mathrm{L} . \mathrm{d})$ operation, the removal rate (in $\mu \mathrm{g} / \mathrm{L} . \mathrm{d})$ was in fact lower in case of the lower loading rate $(2-6 \mu \mathrm{g} / \mathrm{L} . \mathrm{d})$. This can be explained by the fact that if the concentration of a pollutant decrease below a certain threshold level, biodegradation may be hindered due to lack of enzyme induction [24-25]. The results here indicate that carbamazepine is extraordinarily persistent to biodegradation at low concentrations.

Table 1: Carbamazepine removal rare under different loading

\begin{tabular}{ccc}
\hline $\begin{array}{c}\text { Loading rate } \\
(\mu \mathrm{g} / \mathrm{L} . \mathrm{d})\end{array}$ & \multicolumn{2}{c}{ Removal rate } \\
\hline $2-6$ & In percentage $(\%)$ & In mass $(\mu \mathrm{g} / \mathrm{L} . \mathrm{d})$ \\
\hline 750 & 22 & $0.44-1.32$ \\
\hline
\end{tabular}

\subsection{Effect of bioreactor $\mathrm{pH}$}

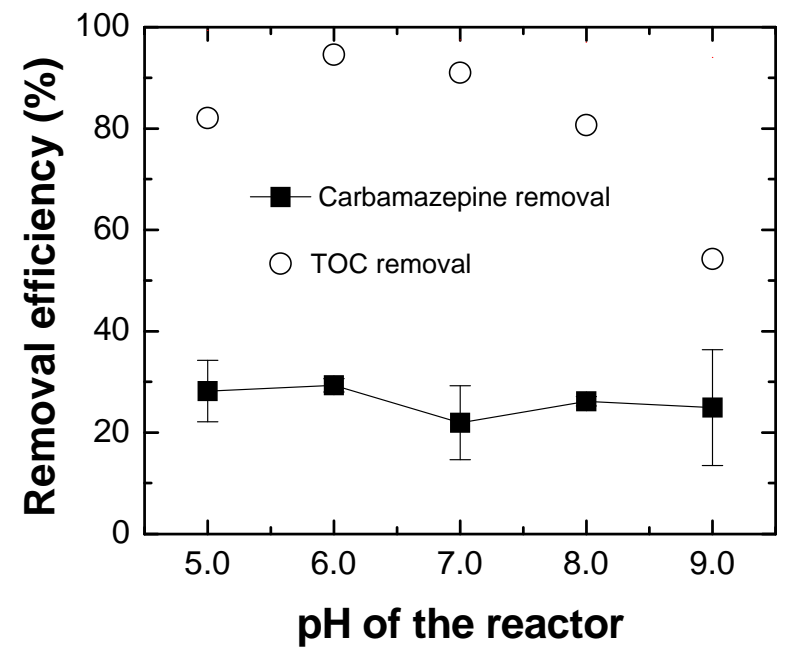

Figure 1: Effect of bioreactor $\mathrm{pH}$ on TOC and carbamazepine removal. Error bars show the standard deviation of 4 measurements.

As can be seen in Figure 1, a small decrease in biological performance with regard to TOC removal efficiency was observed as the mixed liquor $\mathrm{pH}$ was reduced to 5 . A sharp decline in TOC removal efficiency was also observed when the mixed liquor $\mathrm{pH}$ was increased beyond 8. While investigations explicitly studying the effects of $\mathrm{pH}$ on the treatment efficiency of an MBR system remains very limited [22, 26-27], results reported here are in fact consistent with previous studies on conventional activated sludge treatment processes. Lower biological performance at either acidic or basic condition can be attributed to complex changes in the micro-organism fauna of the reactor in response to the mixed liquor $\mathrm{pH}$. In contrast to the TOC removal rate, negligible effect of mixed liquor $\mathrm{pH}$ on carbamazepine removal was observed. An apparent improvement in removal efficiency of certain acidic trace organics such as ibuprofen, ketoprofen, and diclofenac was observed in case of MBRs operated under acidic conditions [11, 22]. This phenomenon was explained by the speciation of the compounds from hydrophilic ionic forms to much more hydrophobic forms at $\mathrm{pH}$ lower than their $p K_{a}$ values which allowed them to adsorb to the activated

Li, X., Hai, F. Ibney., Tadkaew, N., Gilbertson, S. \& Nghiem, L. Duc. (2011). Strategies to enhance the removal of the persistent pharmaceutically active compound carbamazepine by membrane bioreactors. Desalination and Water Treatment, 34 (1-3), $402-407$. 
sludge quite readily. However, carbamazepine used in this study did not speciate as the mixed liquor $\mathrm{pH}$ varied from $\mathrm{pH} 5$ to $\mathrm{pH}$ 9. Consequently, its removal efficiency remained relatively constant and independent of the mixed liquor $\mathrm{pH}$. Carbamazepine contributed a negligible portion of the TOC; hence, mismatch between TOC and carbamazpeine removal profile is not surprising.

\subsection{Effect of DO}

In this study, the effect of DO was studied under the higher loading (750 $\mu \mathrm{g} / \mathrm{L} . \mathrm{d})$ condition. A dramatic effect of operating DO on removal rate was observed (Table 2). In a short-term study conducted by Zwiener and Frimmel [28] diclofenac was better degraded in an anoxic biofilm reactor (62-66\% of its initial concentration). While previous studies have demonstrated relationship of nitrifying condition with carbamazepine removal [29], no literature report could be found which mentions the effect of denitrifying (anoxic) condition on its removal. Our result suggests that anoxic environment promotes carbamazepine degradation. In addition to the possible enhanced biodegradation under anoxic condition, abiotic (chemical conversion) degradation may also be responsible for the observed high removal rate. Further investigation is underway to ascertain the governing reason.

Table 2: Effect of DO on carbamazepine removal

\begin{tabular}{cc}
\hline $\mathrm{DO}, \mathrm{mg} / \mathrm{L}$ & Removal efficiency (\%) \\
\hline$<0.5$ & 67 \\
$2-5$ & 3 \\
\hline
\end{tabular}

\subsection{Effect of MLSS concentration}



Figure 2: Effect of MLSS concentration on carbamazepine removal (under anoxic condition with $\mathrm{DO}<0.5 \mathrm{mg} / \mathrm{L})$.

The effect of MLSS concentration was studied under near-anoxic ( $\mathrm{DO}<0.5 \mathrm{mg} / \mathrm{L})$ condition when the loading rate was $750 \mu \mathrm{g} / \mathrm{L}$.d. The \% removal rate of carbamazepine did not increase much beyond a MLSS concentration of $5 \mathrm{~g} / \mathrm{L}$ or so. This indicates that due to the insignificant affinity of carbamazepine towards adsorption onto sludge, biodegradation, in contrast to biosorption, played the main role in carbamazepine removal in the MBR. In our study, however, under a low MLSS 
concentration of approximately $1 \mathrm{~g} / \mathrm{L}$ the removal rate of carbamazepine was the lowest. This underscores the importance of maintenance of adequate amount of biomass in the reactor to achieve satisfactory degree of recalcitrant pollutant degradation.

\subsection{Adsorption on to activated carbon}

Adsorption onto sludge may facilitate enhanced biodegradation in MBR due to complete sludge retention [30]. The data from our MBR study, however, suggested limited sorption of carbamazepine onto sludge. Accordingly the intrinsic biodegradation rate governed the overall removal of carbamazepine, and due to the hardly biodegradable nature of carbamazepine the extent of removal was rather limited. In an attempt to promote adsorption of carbamazepine and subsequently reap enhanced biodegradation, a strategy of direct addition of adsorbent (e.g., powdered activated carbon, PAC) into MBR may be proposed. In fact, a preliminary batch test demonstrated many fold higher adsorption of carbamazepine onto PAC as compared to MBR sludge (Table 3). Hai et al. [31] previously demonstrated enhanced removal of recalcitrant dyes in a PAC-enhanced MBR. The efficiency of a PAC-enhanced MBR in carbamazepine removal is currently under investigation. Preliminary results indicate that facilitated adsorption can indeed substantially improve the overall carbamazepine removal in MBR (negligible and around 90\% removal without and with PAC addition in MBR).

Table 3: Comparative adsorption of carbamazepine on MBR sludge and PAC

\begin{tabular}{cc}
\hline Media & Unit adsorption of CBZ $(\mathrm{mg} / \mathrm{gm})$ \\
\hline MBR sludge & 0.02 \\
PAC & 287 \\
\hline
\end{tabular}

\section{Conclusions}

Our results indicate that carbamazepine is extraordinarily persistent to biodegradation at low concentrations. Application of slightly acidic $\mathrm{pH}$ may facilitate removal of certain ionizable trace organics which transform to more hydrophobic species under such $\mathrm{pH}$; however, carbamazepine, being a non-ionizable compound, such strategy would be of little significance. In contrast, manipulation of reactor DO appears to be an effective means to achieve high carbamazepine removal. An MBR with alternating anoxic-oxic environment may achieve high removal. On the other hand, negligible sorption of carbamazepine onto sludge implies that maintenance of high MLSS concentration in MBR would not yield significant improvement in overall removal. However, our batch test indicates that enhanced adsorption achieved by powdered activated carbon dosing directly into the MBR may result in enhanced overall removal.

\section{Acknowledgements}

We acknowledge the financial support from the Royal Thai Government to Nichanan Tadkaew and the University of Wollongong tuition fee waiver scholarship to Xueqing Li for doctoral and masters studies, respectively at the University of Wollongong. Zenon Environmental Inc (Ontario, Canada) is thanked for the provision of the submerged membrane module. Activated Carbon Technologies Pty Ltd (Victoria, Australia) is thanked for the provision of PAC sample. Laboratory support from Robert Rowlan is also greatly appreciated.

\section{References}

[1] T.A. Ternes, Occurrence of drugs in German sewage treatment plants and rivers. Water Research, 32(11) (1998): p. 3245-3260.

[2] H.H. Katsuki Kimura, Yoshimasa Watanabe, Removal of pharmaceutical compounds by submerged membrane bioreactors (MBRs). Desalination, 178(1-3) (2005): p. 135-140.

Li, X., Hai, F. Ibney., Tadkaew, N., Gilbertson, S. \& Nghiem, L. Duc. (2011). Strategies to enhance the removal of the persistent pharmaceutically active compound carbamazepine by membrane bioreactors. Desalination and Water Treatment, 34 (1-3), $402-407$. 
[3] Y. Zhang, S.-U. Geiben, and C. Gal, Carbamazepine and diclofenac: Removal in wastewater treatment plants and occurrence in water bodies. Chemosphere, 73(8) (2008): p. 1151.

[4] T. Heberer, Tracking persistent pharmaceutical residues from municipal sewage to drinking water. Journal of Hydrology, 266(3-4) (2002): p. 175-189.

[5] S. Weigel, K. Bester, and H. Hühnerfuss, New method for rapid solid-phase extraction of large-volume water samples and its application to non-target screening of North Sea water for organic contaminants by gas chromatography-mass spectrometry. Journal of Chromatography A, 912(1) (2001): p. 151-161.

[6] K. Osenbruck, H.-R. Glaser, K. Knoller, S.M. Weise, M. Moder, R. Wennrich, M. Schirmer, F. Reinstorf, W. Busch, and G. Strauch, Sources and transport of selected organic micropollutants in urban groundwater underlying the city of Halle (Saale), Germany. Water Research, 41(15) (2007): p. 3259-3270.

[7] J.E. Drewes, T. Heberer, and K. Reddersen, Fate of pharmaceuticals during indirect potable reuse, in Water Science and Technology. 2002. p. 73-80.

[8] N. Nakada, H. Shinohara, A. Murata, K. Kiri, S. Managaki, N. Sato, and H. Takada, Removal of selected pharmaceuticals and personal care products (PPCPs) and endocrinedisrupting chemicals (EDCs) during sand filtration and ozonation at a municipal sewage treatment plant. Water Research, 41(19) (2007): p. 4373-4382.

[9] M. Clara, N. Kreuzinger, B. Strenn, O. Gans, and H. Kroiss, The solids retention time--a suitable design parameter to evaluate the capacity of wastewater treatment plants to remove micropollutants. Water Research, 39(1) (2005): p. 97-106.

[10] J. Zhang, H.C. Chua, J. Zhou, and A.G. Fane, Factors affecting the membrane performance in submerged membrane bioreactors. Journal of Membrane Science, 284(1-2) (2006): p. 54.

[11] A.A. Alturki, N. Tadkaew, J.A. McDonald, S.J. Khan, W.E. Price, and L.D. Nghiem, Combining MBR and NF/RO membrane filtration for the removal of trace organics in indirect potable water reuse applications. Journal of Membrane Science, 365(1-2) (2010): p. 206-215

[12] B.J. Vanderford and S.A. Snyder, Analysis of pharmaceuticals in water by isotope dilution liquid chromatography/tandem mass spectrometry. Environmental Science \& Technology, 40(23) (2006): p. 7312-7320.

[13] L.S. Clescerl, A.E. Greenberg, and A.D. Eaton, Standard Methods for Examination of Water \& Wastewater $21^{\text {st }}$ ed. 2005: American Public Health Association

[14] D. Löffler, J. Römbke, M. Meller, and T.A. Ternes, Environmental fate of pharmaceuticals in water/sediment systems. Environmental Science and Technology, 39(14) (2005): p. 52095218.

[15] K. Stamatelatou, Frouda, C., Fountoulakis, M.S., Drillia, P., Kornaros, M., Lyberatos, and G., Pharmaceuticals and health care products in wastewater effluents: the example of carbamazepine. . Water Science and Technology: Water Supply 3(2003): p. 131-137.

[16] A. Joss, S. Zabczynski, A. Göbel, B. Hoffmann, D. Löffler, C.S. McArdell, T.A. Ternes, A. Thomsen, and H. Siegrist, Biological degradation of pharmaceuticals in municipal wastewater treatment: Proposing a classification scheme. Water Research, 40(8) (2006): p. 1686.

[17] S.D. Kim, J. Cho, I.S. Kim, B.J. Vanderford, and S.A. Snyder, Occurrence and removal of pharmaceuticals and endocrine disruptors in South Korean surface, drinking, and waste waters. Water Research, 41(5) (2007): p. 1013-1021.

[18] C. Abegglen, A. Joss, C.S. McArdell, G. Fink, M.P. Schlüsener, T.A. Ternes, and H. Siegrist, The fate of selected micropollutants in a single-house MBR. Water Research, 43(7) (2009): p. 2036-2046.

Li, X., Hai, F. Ibney., Tadkaew, N., Gilbertson, S. \& Nghiem, L. Duc. (2011). Strategies to enhance the removal of the persistent pharmaceutically active compound carbamazepine by membrane bioreactors. Desalination and Water Treatment, 34 (1-3), 402-407. 
[19] J. Radjenovic, M. Petrovic, and D. Barceló, Fate and distribution of pharmaceuticals in wastewater and sewage sludge of the conventional activated sludge (CAS) and advanced membrane bioreactor (MBR) treatment. Water Research, 43(3) (2009): p. 831-841.

[20] M. Bernhard, J. Müller, and T.P. Knepper, Biodegradation of persistent polar pollutants in wastewater: Comparison of an optimised lab-scale membrane bioreactor and activated sludge treatment. Water Research, 40(18) (2006): p. 3419-3428.

[21] N. Kreuzinger, M. Clara, B. Strenn, and H. Kroiss, Relevance of the sludge retention time (SRT) as design criteria for wastewater treatment plants for the removal of endocrine disruptors and pharmaceuticals from wastewater. Water Science and Technology, 50(5) (2004): p. 149-156.

[22] T. Urase, C. Kagawa, and T. Kikuta, Factors affecting removal of pharmaceutical substances and estrogens in membrane separation bioreactors. Desalination, 178(1-3) (2005): p. 107-113.

[23] N. Tadkaew, M. Sivakumar, S.J. Khan, J.A. McDonald, and L.D. Nghiem, Effect of mixed liquor $\mathrm{pH}$ on the removal of trace organic contaminants in a membrane bioreactor. Bioresource Technology, 101(5) (2010): p. 1494-1500.

[24] C.G. Dosoretz and K.W. Böddeker, Removal of trace organics from water using a pumped bed-membrane bioreactor with powdered activated carbon. Journal of Membrane Science, 239(1) (2004): p. 81-90.

[25] K. Kovarova-Kovar and T. Egli, Growth kinetics of suspended microbial cells: From singlesubstrate- controlled growth to mixed-substrate kinetics. Microbiology and Molecular Biology Reviews, 62(3) (1998): p. 646-666.

[26] D.D. Baldwin and C.E. Campbell, Short-term effects of low $p H$ on the microfauna of an activated sludge wastewater treatment system. Water Quality Research Journal of Canada, 36(3) (2001): p. 519-535.

[27] T. Zhang, Y. Liu, and H.H.P. Fang, Effect of $p H$ change on the performance and microbial community of enhanced biological phosphate removal process. Biotechnology and Bioengineering, 92(2) (2005): p. 173-182.

[28] C. Zwiener and F.H. Frimmel, Short-term tests with a pilot sewage plant and biofilm reactors for the biological degradation of the pharmaceutical compounds clofibric acid, ibuprofen, and diclofenac. Science of the Total Environment, 309(1-3) (2003): p. 201-211.

[29] N.H. Tran, T. Urase, and O. Kusakabe, The characteristics of enriched nitrifier culture in the degradation of selected pharmaceutically active compounds. Journal of Hazardous Materials, 171(1-3) (2009): p. 1051-1057.

[30] F.I. Hai, K. Yamamoto, and K. Fukushi, Development of a submerged membrane fungi reactor for textile wastewater treatment. Desalination, 192(1-3) (2006): p. 315-322.

[31] F.I. Hai, K. Yamamoto, F. Nakajima, and K. Fukushi, Removal of structurally different dyes in submerged membrane fungi reactor--Biosorption/PAC-adsorption, membrane retention and biodegradation. Journal of Membrane Science, 325(1) (2008): p. 395-403. 